Article

\title{
Saving the Planet's Climate or Water Resources? The Trade-Off between Carbon and Water Footprints of European Biofuels
}

\author{
Markus Berger ${ }^{1, *}$, Stephan Pfister ${ }^{2}$, Vanessa Bach ${ }^{1}$ and Matthias Finkbeiner ${ }^{1}$ \\ 1 Chair of Sustainable Engineering, Department of Environmental Technology, \\ Technische Universität Berlin, 10623 Berlin, Germany; \\ E-Mails: vanessa.bach@tu-berlin.de (V.B.); matthias.finkbeiner@tu-berlin.de (M.F.) \\ 2 ETH Zürich, Institute of Environmental Engineering, 8093 Zurich, Switzerland; \\ E-Mail: stephan.pfister@ifu.baug.ethz.ch
}

* Author to whom correspondence should be addressed; E-Mail: markus.berger@tu-berlin.de; Tel.: +49-30-314-25084.

Academic Editor: Arjen Y. Hoekstra

Received: 2 March 2015 / Accepted: 19 May 2015 / Published: 26 May 2015

\begin{abstract}
Little information regarding the global water footprint of biofuels consumed in Europe is available. Therefore, the ultimate origin of feedstock underlying European biodiesel and bioethanol consumption was investigated and combined with the irrigation requirements of different crops in different countries. A (blue) water consumption of $1.9 \mathrm{~m}^{3}$ in 12 countries per GJ of European biodiesel and $3.3 \mathrm{~m}^{3}$ in 23 countries per GJ of bioethanol was determined. Even though this represents an increase by a factor of 60 and 40 compared to fossil diesel and gasoline, these figures are low compared to global average data. The assessment of local consequences has shown that the irrigation of sunflower seed in Spain causes $50 \%$ of the impacts resulting from biodiesel-even though it constitutes only $0.9 \%$ of the feedstock. In case of bioethanol production, the irrigation of sugar cane in Egypt, which constitutes only $0.7 \%$ of the underlying feedstock, causes $20 \%$ of the impacts. In a case study on passenger cars, it was shown that biofuels can reduce the global warming potential by circa $50 \%$ along the product life cycle. However, the price of this improvement is an approximate 19 times increased water consumption, and resulting local impacts are even more severe.
\end{abstract}

Keywords: water footprint; carbon footprint; biofuels; cars; transport 


\section{Introduction}

Taking into account the European Union's targets to reduce both $\mathrm{CO}_{2}$ emissions and its dependency on fossil fuels, biofuels such as biodiesel and bioethanol gained increasing attention during the last years. Fixed in the Renewable Energy Directive (RED) [1], the European Commission committed itself to reach a share of $10 \%$ of energy in road transport coming from renewable sources in each of the member states by 2020. Even though this includes hydrogen or electricity produced from renewable sources as well, biofuels are expected to be the most relevant fuels to reach this goal [2].

While the RED demands certain sustainability criteria to be met, such as the ban of cultivation of energy plants on land with high biodiversity and high carbon stocks, the environmental sustainability of biofuels is debated. Biofuels are not 'carbon neutral' as the cultivation and harvesting of energy plants as well as the production of the biofuels requires fertilizers, agricultural machinery, processing equipment and chemicals which all cause fossil $\mathrm{CO}_{2}$ emissions during their production. Taking into account these aspects, recent life cycle assessment [3] and carbon footprint [4] studies determined a reduction potential in the global warming potential (GWP) of up to $\sim 50 \%$ for biodiesel (soy bean, US) and $\sim 65 \%$ for bioethanol (sugar cane, Brazil) compared to their fossil alternatives [5]. Even though this study shows that the minimum GWP reduction of currently $35 \%$ (50\% in $2017,60 \%$ in 2018 ) required by the RED is met in many cases, some scientists predict lower GWP reduction rates when considering GHG emissions resulting from the indirect land use effect [6]. However, due to the lack of scientific robustness, international standards do not require the inclusion of these indirect effects [7].

Despite these discussions, biofuels tend to show a more or less distinct advantage when it comes to the reduction of GHG emission. However, in comparisons to fossil fuels, it is often forgotten that the production of biodiesel and bioethanol can require a lot of water, mainly in the cultivation of crops. Studies of Gerbens-Leenes and colleagues [8] have shown that up to 11,636 L of "green", "blue", and "gray" water is needed to produce $1 \mathrm{~L}$ of biodiesel from jatropha and the production of $1 \mathrm{~L}$ of bioethanol from sorghum can require up to $4254 \mathrm{~L}$ of water, even though these plants are not used as a source of European biofuel production. Taking into account the facts that water consumption grew twice as fast as the world's population during the past century and that more than 1 billion people live in water stressed areas, the neglecting of this aspect is a severe deficit in the discussion of international biofuel strategies. In a nutshell, this trade-off can be summarized as: Which water footprint increase do we need to accept for a carbon footprint decrease?

In order to tackle this question, this paper determines the water footprint of the European biodiesel and bioethanol consumption mixes and compares them to their fossil alternatives diesel and gasoline. On the inventory level, the volumes of blue water consumed in the global production of the underlying crops as well as in the crude oil production and refinery steps are investigated. As this study represents a water availability footprint according to ISO 14064 [9], green and gray water consumption are excluded here but can be reviewed in the works of Gerbens-Leenes and Hoekstra [10]. In order to allow for comparability, a functional unit of $1 \mathrm{GJ}$ of fuel has been chosen, which equates to $31 \mathrm{~L}$ of biodiesel, $47 \mathrm{~L}$ of bioethanol, $28 \mathrm{~L}$ of diesel and $33 \mathrm{~L}$ of gasoline. Since the determination of water consumption volumes represents the first step in a water footprint analysis only [9], resulting local impacts are determined using recently developed impact assessment models. Finally, the influence of 
biofuels on the carbon and water footprint of a car is estimated taking into account the entire product life cycle.

\section{Methodology}

\subsection{Water Inventory}

Taking into account the findings of previous studies accomplished by Mekonnen and Hoekstra [11], it was assumed that relevant water consumption in the production of both biodiesel and bioethanol occurs only in the cultivation of the underlying crops resulting from irrigation. Here it should be noted, that water consumption refers to the fraction of total withdrawal which is not returned to the originating catchment area, mainly due to evapotranspiration [12]. As irrigation water needs highly depend on the crop and the location it is grown, the shares and origins of specific crops underlying the European consumption of biodiesel and ethanol need to be determined. Based on a study of Ecofys [13], Gerasimchuk [2] determined the ultimate origin of feedstock underlying the European biodiesel and bioethanol consumption in 2010 (Tables 1 and 2). The underlying surveys also acknowledge triangular trade, e.g., the import of biodiesel from Argentina and Indonesia via the US. Moreover, the figures presented relate to the ultimate origin of feedstock. Thus, it is considered that the underlying crops used for the production of biofuels in a certain country can come from other countries as well. In order to provide a higher spatial resolution, total amounts derived from the European Union have been disaggregated based on the production shares of the individual crops on member state level derived from FAO data [14].

Subsequently, the country specific production volumes underlying European biodiesel (Table 1) and bioethanol (Table 2) consumption mixes have been combined with information regarding their country specific irrigation requirements. For this, the blue water footprint of biodiesel (Table 3) and bioethanol (Table 4) produced from different crops in different countries derived from the WaterStat Database ([11] reference year1996-2005) has been used.

The average water consumption per GJ of European biofuel has been calculated by dividing the total volume of water consumed to irrigate the underlying crops by the total amount of biodiesel (Table 1) and bioethanol (Table 2).

The water consumption per GJ of fossil diesel and gasoline has been determined with the GaBi 6 database [15] by using the water consumption figures of the EU27 fuel mixes (reference year 2013).

In order to assess local consequences of water consumption, the volumetric inventory information is not sufficient and spatial information is the minimum requirement for all impact assessment methods [16]. In case of biofuels, spatial data is available as the inventories have been determined based on the underlying feedstock and its origin. For fossil fuels, the location of water consumption was determined in a top-down regionalization approach introduced by Berger and colleagues $[17,18]$. By means of the GaBi 6 database, the total water consumption of diesel and gasoline has been subdivided into the shares of water consumed at the crude oil production and at the refineries. These shares have been allocated to different countries based on the European crude oil consumption mix and on the location of European refineries [15]. 
In addition to the absolute water consumption volumes, the spatially explicit water inventories show the location of water consumption along the supply chains of biodiesel, bioethanol, fossil diesel, and gasoline.

Table 1. Origin of crops underlying the European biodiesel consumption mix in 2010 $\left(10^{3} \mathrm{GJ}\right)$ [2,14]; gray color indicates exclusion from water footprint calculation as the origin is unknown or the feedstock is a waste.

\begin{tabular}{|c|c|c|c|c|c|c|c|c|}
\hline & Rapeseed & Soybean & Oil palm & Sunflower & Tallow & RVO & Other & Total \\
\hline European Union & 171,583 & 3643 & 209 & 18,590 & 6657 & 49,490 & 126 & 250,299 \\
\hline Austria & - & 288 & - & - & - & - & - & 392 \\
\hline Bulgaria & - & - & - & 4043 & - & - & - & 4043 \\
\hline Croatia & - & 387 & - & 273 & - & - & - & 659 \\
\hline Czech Republic & 13,050 & - & - & - & - & - & - & 13,050 \\
\hline Denmark & 6203 & - & - & - & - & - & - & 6203 \\
\hline France & 39,516 & 383 & - & 3303 & - & - & - & 43,203 \\
\hline Germany & 52,305 & - & - & - & - & - & - & 52,409 \\
\hline Greece & - & - & - & 703 & - & - & - & 703 \\
\hline Hungary & 4769 & 285 & - & 3068 & - & - & - & 8122 \\
\hline Italy & - & 1641 & - & 467 & - & - & - & 2108 \\
\hline Lithuania & 4962 & - & - & - & - & - & - & 4962 \\
\hline Poland & 24,213 & - & - & - & - & - & - & 24,213 \\
\hline Romania & 6349 & 521 & - & 4585 & - & - & - & 11,455 \\
\hline Slovakia & - & 138 & - & - & - & - & - & 138 \\
\hline Spain & 974 & - & - & 2,149 & - & - & - & 3123 \\
\hline United Kingdom & 19,242 & - & - & - & - & - & - & 19,242 \\
\hline Argentina & - & 49,867 & - & - & - & - & - & 49,867 \\
\hline Indonesia & - & - & 34,082 & - & - & - & - & 34,082 \\
\hline Brazil & - & 17,460 & - & - & 42 & - & - & 17,502 \\
\hline Canada & 8876 & 1842 & - & - & 544 & 921 & - & 12,184 \\
\hline Ukraine & 10,551 & 586 & - & - & - & - & - & 11,137 \\
\hline US & 293 & 9253 & - & - & 502 & 209 & - & 10,258 \\
\hline Malaysia & - & - & 8876 & - & - & - & - & 8876 \\
\hline Paraguay & 126 & 7746 & - & - & - & - & - & 7872 \\
\hline Russia & 3350 & 1884 & - & - & - & - & - & 5234 \\
\hline China & - & 42 & - & - & - & 2805 & - & 2847 \\
\hline Others & 4145 & 586 & 544 & - & - & 42 & - & 5317 \\
\hline Total & 198,924 & 92,910 & 43,712 & 18,590 & 7746 & 53,468 & 126 & 415,476 \\
\hline Share & $48 \%$ & $22 \%$ & $11 \%$ & $4 \%$ & $2 \%$ & $13 \%$ & $0 \%$ & \\
\hline
\end{tabular}


Table 2. Origin of crops underlying the European bioethanol consumption mix in 2010 $\left(10^{3} \mathrm{GJ}\right)$ [2,14]; gray color indicates exclusion from water footprint calculation as the origin is unknown.

\begin{tabular}{|c|c|c|c|c|c|c|c|c|c|c|}
\hline & Wheat & Maize & Barley & Rye & Triti-cale & $\begin{array}{c}\text { Sugar } \\
\text { Beet }\end{array}$ & Wine & $\begin{array}{c}\text { Sugar } \\
\text { Cane }\end{array}$ & Others & Total \\
\hline European Union & 24,326 & 14,403 & 2428 & 3391 & 837 & 30,691 & 4229 & - & 1382 & 81,688 \\
\hline Austria & - & 382 & - & - & - & 1119 & - & - & - & 1501 \\
\hline Belgium & - & - & - & - & - & 1430 & - & - & - & 1430 \\
\hline Bulgaria & 1072 & 536 & - & - & - & - & - & - & - & 1609 \\
\hline Croatia & - & 437 & - & - & - & - & - & - & - & 437 \\
\hline Czech Republic & 989 & - & 72 & - & - & 1209 & - & - & - & 2270 \\
\hline Denmark & 871 & - & 179 & 199 & - & - & - & - & - & 1249 \\
\hline Finland & - & - & 86 & - & - & - & - & - & - & 86 \\
\hline France & 8124 & 3511 & 467 & - & - & 10,852 & - & - & - & 22,953 \\
\hline Germany & 5264 & 1023 & 468 & 1775 & - & 7370 & - & - & - & 15,900 \\
\hline Greece & 334 & 510 & - & - & - & - & - & - & - & 843 \\
\hline Hungary & 1072 & 1568 & - & - & - & - & - & - & - & 2640 \\
\hline Ireland & - & - & 75 & - & - & - & - & - & - & 75 \\
\hline Italy & 1475 & 1517 & - & - & - & - & - & - & - & 2991 \\
\hline The Netherlands & - & - & - & - & - & 1849 & - & - & - & 1849 \\
\hline Poland & 1992 & 943 & 132 & 1272 & - & 3419 & - & - & - & 7758 \\
\hline Portugal & - & 198 & - & - & - & - & - & - & - & 198 \\
\hline Romania & 1535 & 2646 & 70 & - & - & - & - & - & - & 4251 \\
\hline Spain & 1599 & 1132 & 455 & 145 & - & 860 & - & - & - & 4190 \\
\hline Sweden & - & - & 88 & - & - & - & - & - & - & 88 \\
\hline United Kingdom & - & - & 321 & - & - & 2583 & - & - & - & 2904 \\
\hline Brazil & - & 335 & - & - & - & - & - & 9798 & - & 10,133 \\
\hline USA & 84 & 5108 & - & - & - & - & - & - & - & 5192 \\
\hline Peru & - & - & - & - & - & - & - & 1089 & - & 1089 \\
\hline Switzerland & 1047 & - & - & - & - & - & - & - & - & 1047 \\
\hline Bolivia & - & - & - & - & - & - & - & 837 & - & 837 \\
\hline Ukraine & 209 & 293 & - & - & - & 84 & - & - & - & 586 \\
\hline Egypt & - & - & - & - & - & - & - & 628 & - & 628 \\
\hline Guatemala & - & - & - & - & - & - & - & 586 & - & 586 \\
\hline Argentina & - & 84 & - & - & - & - & - & 209 & - & 293 \\
\hline Cuba & - & - & - & - & - & - & - & 251 & - & 251 \\
\hline Other & 419 & 293 & - & - & - & - & - & 670 & 84 & 1465 \\
\hline Total & 26,085 & 20,516 & 2412 & 3391 & 837 & 30,774 & 4229 & 14,068 & 1465 & 103,780 \\
\hline
\end{tabular}


Table 3. Specific irrigation water consumption of crops (1996-2005) underlying the European biodiesel consumption $\left(\mathrm{m}^{3} / \mathrm{GJ}\right)[11]$.

\begin{tabular}{|c|c|c|c|c|}
\hline & Rapeseed & Soybean & Oil Palm & Sunflower \\
\hline \multicolumn{5}{|l|}{ European Union } \\
\hline Austria & - & 0.00 & 0.00 & - \\
\hline Bulgaria & - & - & - & 0.38 \\
\hline Croatia & - & 0.00 & - & 0.00 \\
\hline Czech Republic & 0.00 & - & - & - \\
\hline Denmark & 0.00 & - & - & - \\
\hline France & 0.43 & 71.54 & - & 1.55 \\
\hline Germany & 0.00 & - & 0.00 & - \\
\hline Greece & - & - & - & 90.94 \\
\hline Hungary & 3.87 & 0.98 & - & 0.21 \\
\hline Italy & - & 20.95 & - & 9.60 \\
\hline Lithuania & 0.00 & - & - & - \\
\hline Poland & 0.00 & - & - & - \\
\hline Romania & 0.00 & 103.10 & - & 16.44 \\
\hline Slovakia & - & 24.19 & - & - \\
\hline Spain & 6.02 & - & - & 128.06 \\
\hline United Kingdom & 0.00 & - & - & - \\
\hline Argentina & - & 0.85 & - & - \\
\hline Indonesia & - & - & 0.00 & - \\
\hline Brazil & - & 0.13 & - & - \\
\hline Canada & 0.00 & 0.00 & - & - \\
\hline Ukraine & 0.00 & 0.00 & - & - \\
\hline US & 1.76 & 14.79 & - & - \\
\hline Malaysia & - & - & 0.00 & - \\
\hline Paraguay & 0.00 & 0.00 & - & - \\
\hline Russia & 0.00 & 0.00 & - & - \\
\hline China & - & 39.89 & - & - \\
\hline
\end{tabular}


Table 4. Specific irrigation water consumption of crops (1996-2005) underlying the European bioethanol consumption $\left(\mathrm{m}^{3} / \mathrm{GJ}\right)[11]$.

\begin{tabular}{|c|c|c|c|c|c|c|}
\hline & Wheat & Maize & Barley & Rye & Sugar beet & Sugar cane \\
\hline \multicolumn{7}{|l|}{ European Union } \\
\hline Austria & - & 0.00 & - & - & 1.40 & - \\
\hline Belgium & - & - & - & - & 0.01 & - \\
\hline Bulgaria & 0.00 & 1.65 & - & - & - & - \\
\hline Croatia & - & 0.03 & - & - & - & - \\
\hline Czech Republic & 0.00 & - & 0.00 & - & 0.00 & - \\
\hline Denmark & 0.62 & - & 0.02 & 0.00 & - & - \\
\hline Finland & - & - & 0.00 & - & - & - \\
\hline France & 0.13 & 9.00 & 0.40 & - & 0.48 & - \\
\hline Germany & 0.00 & 0.21 & 0.00 & 0.00 & 1.04 & - \\
\hline Greece & 2.83 & 49.38 & - & - & - & - \\
\hline Hungary & 0.18 & 0.11 & - & - & - & - \\
\hline Ireland & - & - & 0.00 & - & - & - \\
\hline Italy & 1.58 & 10.75 & - & - & - & - \\
\hline The Netherlands & - & - & - & - & 0.08 & - \\
\hline Poland & 0.04 & 0.37 & 0.00 & 0.02 & 0.22 & - \\
\hline Portugal & - & 86.00 & - & - & - & - \\
\hline Romania & 4.47 & 1.93 & 0.00 & - & - & - \\
\hline Spain & 4.68 & 40.43 & 8.23 & 0.00 & 21.63 & - \\
\hline Sweden & - & - & 0.00 & - & - & - \\
\hline United Kingdom & - & - & 0.00 & - & 0.33 & - \\
\hline Brazil & - & 0.05 & - & - & - & 2.32 \\
\hline USA & 9.04 & 6.31 & - & - & - & - \\
\hline Peru & - & - & - & - & - & 26.09 \\
\hline Switzerland & 0.00 & - & - & - & - & - \\
\hline Bolivia & - & - & - & - & - & 3.92 \\
\hline Ukraine & 1.85 & 8.66 & - & - & 1.02 & - \\
\hline Egypt & - & - & - & - & - & 61.93 \\
\hline Guatemala & - & - & - & - & - & 5.40 \\
\hline Argentina & - & 1.40 & - & - & - & 11.70 \\
\hline Cuba & - & - & - & - & - & 21.53 \\
\hline
\end{tabular}

\subsection{Impact Assessment}

After the water inventory was determined, an impact assessment has been conducted in order to evaluate the local consequences resulting from the water consumption in the different regions.

For this, the water accounting and vulnerability evaluation (WAVE) model [19] and the impact assessment model of Pfister and colleagues [20] have been applied. Both methods rely on local freshwater scarcity which is calculated by relating annual water use (in case of WAVE water consumption) to annual freshwater availability (groundwater recharge and surface run-off). Such ratios have been determined for more than 11,000 river basins on a global level by means of the hydrological model WaterGAP2 [21] which provides annual average hydrological information based on the climate 
normal period (1961-1990). Based on these scarcity ratios and further hydrologic parameters, the WAVE model determines regional water depletion indexes (WDI) which denote the risk that water consumption leads to freshwater depletion (Figure 1).

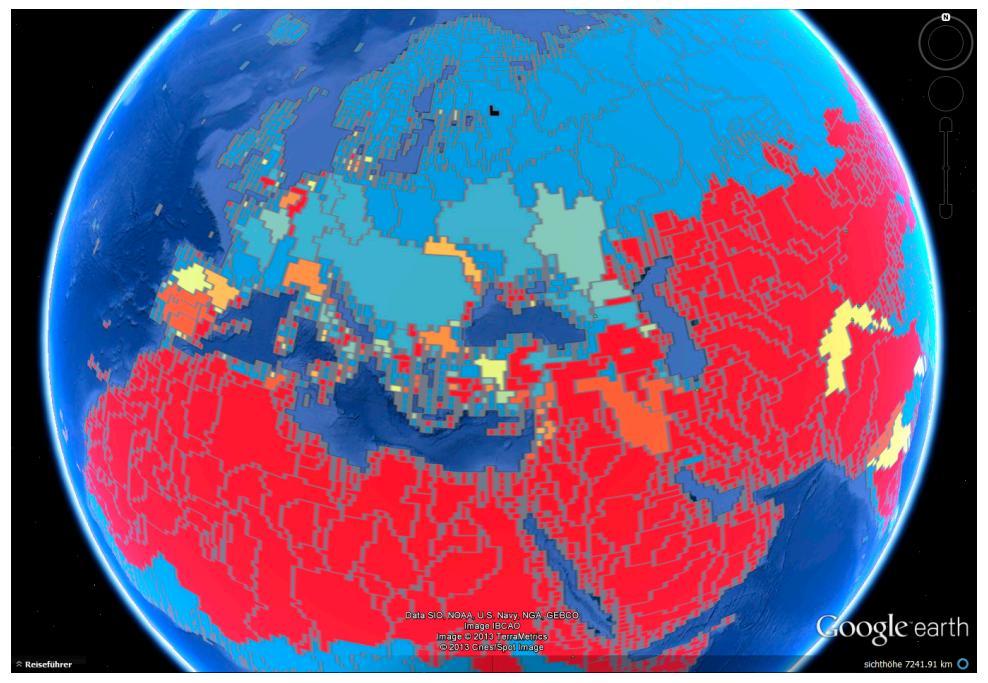

Figure 1. Water depletion index (WDI), which denotes the risk that water consumption leads to freshwater depletion, ranging from 0.01 (blue) to 1.00 (red) - Google Earth layer can be downloaded free of charge at http://www.see.tu-berlin.de/WAVE.

The model of Pfister and colleagues also provides a general scarcity based indicator (water stress index) and additionally assesses damages resulting from water consumption specifically for human health, ecosystems, and resources according to the procedure described in ref. [20]. While all impact factors have been developed on the spatial resolution of river basins, national average factors have been derived by creating water consumption weighted averages for each country.

The overall impacts per GJ of biodiesel, bioethanol, fossil diesel, and fossil gasoline have been determined by multiplying their spatially explicit water inventories by the corresponding national impact factors and aggregating the local impacts.

\subsection{Influence of Biofuels on Carbon and Water Footprint of Cars along the Life Cycle}

In order to compare the carbon and water footprint of cars run by fossil fuels and biofuels, GHG emissions and water consumption of a car's production and recycling phases have been estimated based on existing studies [17,22,23]. Assuming a mileage of 200,000 km and an average fuel consumption of $9 \mathrm{~L}$ gasoline per $100 \mathrm{~km}$ (and $13.8 \mathrm{~L}$ bioethanol, both equals $369 \mathrm{MJ}$ ) the global warming potential and the water consumption of a car's use phase has been estimated. An average emission of $2.5 \mathrm{~kg} \mathrm{CO}_{2}$ per L gasoline and a reduction of $60 \%$ [24] have been assumed. For water, the consumption figures determined for gasoline and biofuels in this paper have been used. In addition to the volumetric information, impacts resulting from water consumption along the product life cycle have been assessed by means of the WAVE model [19]. 


\section{Results and Discussion}

\subsection{Water Inventories}

By connecting the information regarding the crops and their origins underlying European biodiesel and bioethanol consumption (Tables 1 and 2) with the crop-specific national irrigation requirements (Tables 3 and 4), the total volume of water consumed around the globe for the provision of European biofuels has been determined (Tables 5 and 6).

Table 5. Total (blue) water consumption of crops underlying the European biodiesel consumption $\left(10^{6} \mathrm{~m}^{3}\right)$.

\begin{tabular}{ccccccc}
\hline & Rapeseed & Soybean & Oil palm & Sunflower & Total & Share \\
\hline European Union & 41.3 & 119.1 & 0.0 & 426.2 & 586.7 & $76 \%$ \\
Austria & - & 0.0 & - & - & 0.0 & $0 \%$ \\
Bulgaria & - & - & - & 1.5 & 1.5 & $0 \%$ \\
Croatia & - & 0.0 & - & 0.0 & 0.0 & $0 \%$ \\
Czech Republic & 0.0 & - & - & - & 0.0 & $0 \%$ \\
Denmark & 0.0 & - & - & - & 0.0 & $0 \%$ \\
France & 17.0 & 27.4 & - & 5.1 & 49.5 & $6 \%$ \\
Germany & 0.0 & - & - & - & 0.0 & $0 \%$ \\
Greece & - & - & - & 63.9 & 63.9 & $8 \%$ \\
Hungary & 18.5 & 0.3 & - & 0.6 & 19.4 & $3 \%$ \\
Italy & - & 34.4 & - & 4.5 & 38.9 & $5 \%$ \\
Lithuania & 0.0 & - & - & - & 0.0 & $0 \%$ \\
Poland & 0.0 & - & - & - & 0.0 & $0 \%$ \\
Romania & 0.0 & 53.7 & - & 75.4 & 129.1 & $17 \%$ \\
Slovakia & - & 3.3 & - & - & 3.3 & $0 \%$ \\
Spain & 5.9 & - & - & 275.2 & 281.0 & $36 \%$ \\
United Kingdom & 0.0 & - & - & - & 0.0 & $0 \%$ \\
Argentina & - & 42.4 & - & - & 42.4 & $6 \%$ \\
Indonesia & - & - & 0.0 & - & 0.0 & $0 \%$ \\
Brazil & - & 2.3 & - & - & 2.3 & $0 \%$ \\
Canada & 0.0 & 0.0 & - & - & 0.0 & $0 \%$ \\
Ukraine & 0.0 & 0.0 & - & - & 0.0 & $0 \%$ \\
US & 0.5 & 136.9 & - & - & 137.4 & $18 \%$ \\
Malaysia & - & - & 0.0 & - & 0.0 & $0 \%$ \\
Paraguay & 0.0 & 0.0 & - & - & 0.0 & $0 \%$ \\
Russia & 0.0 & 0.0 & - & - & 0.0 & $0 \%$ \\
China & - & 2 & - & - & 1.7 & $0 \%$ \\
Total & 41.8 & 302.3 & 0.0 & 426.2 & 770.4 & $100 \%$ \\
Share & $5 \%$ & $39 \%$ & $0 \%$ & $55 \%$ & $100 \%$ & \\
\hline & & & & & &
\end{tabular}


Table 6. Total (blue) water consumption of crops underlying the European bioethanol consumption $\left(10^{6} \mathrm{~m}^{3}\right)$.

\begin{tabular}{|c|c|c|c|c|c|c|c|c|}
\hline & Wheat & Maize & Barley & Rye & Sugar beet & Sugar cane & Total & Share \\
\hline European Union & 19.5 & 142.6 & 3.9 & 0.0 & 34.8 & 0.0 & 200.9 & $59 \%$ \\
\hline Austria & - & 0.0 & - & - & 1.6 & - & 1.6 & $0 \%$ \\
\hline Belgium & - & - & - & - & 0.0 & - & 0.0 & $0 \%$ \\
\hline Bulgaria & 0.0 & 0.9 & - & - & - & - & 0.9 & $0 \%$ \\
\hline Croatia & - & 0.0 & - & - & - & - & 0.0 & $0 \%$ \\
\hline Czech Republic & 0.0 & - & 0.0 & - & 0.0 & - & 0.0 & $0 \%$ \\
\hline Denmark & 0.5 & - & 0.0 & 0.0 & - & - & 0.5 & $0 \%$ \\
\hline Finland & - & - & 0.0 & - & - & - & 0.0 & $0 \%$ \\
\hline France & 1.1 & 31.6 & 0.2 & - & 5.2 & - & 38.0 & $11 \%$ \\
\hline Germany & 0.0 & 0.2 & 0.0 & 0.0 & 7.7 & - & 7.9 & $2 \%$ \\
\hline Greece & 0.9 & 25.2 & - & - & - & - & 26.1 & $8 \%$ \\
\hline Hungary & 0.2 & 0.2 & - & - & - & - & 0.4 & $0 \%$ \\
\hline Ireland & - & - & 0.0 & - & - & - & 0.0 & $0 \%$ \\
\hline Italy & 2.3 & 16.3 & - & - & - & - & 18.6 & $5 \%$ \\
\hline The Netherlands & - & - & - & - & 0.1 & - & 0.1 & $0 \%$ \\
\hline Poland & 0.1 & 0.3 & 0.0 & 0.0 & 0.8 & - & 1.2 & $0 \%$ \\
\hline Portugal & - & 17.0 & - & - & - & - & 17.0 & $5 \%$ \\
\hline Romania & 6.9 & 5.1 & 0.0 & - & - & - & 12.0 & $4 \%$ \\
\hline Spain & 7.5 & 45.8 & 3.7 & 0.0 & 18.6 & - & 75.6 & $22 \%$ \\
\hline Sweden & - & - & 0.0 & - & - & - & 0.0 & $0 \%$ \\
\hline United Kingdom & - & - & 0.0 & - & 0.9 & - & 0.9 & $0 \%$ \\
\hline Brazil & - & 0.0 & - & - & - & 22.7 & 22.7 & $7 \%$ \\
\hline USA & 0.8 & 32.2 & - & - & - & - & 33.0 & $10 \%$ \\
\hline Peru & - & - & - & - & - & 28.4 & 28.4 & $8 \%$ \\
\hline Switzerland & 0.0 & - & - & - & - & - & 0.0 & $0 \%$ \\
\hline Bolivia & - & - & - & - & - & 3.3 & 3.3 & $1 \%$ \\
\hline Ukraine & 0.4 & 2.5 & - & - & 0.1 & - & 3.0 & $1 \%$ \\
\hline Egypt & - & - & - & - & - & 38.9 & 38.9 & $11 \%$ \\
\hline Guatemala & - & - & - & - & - & 3.2 & 3.2 & $1 \%$ \\
\hline Argentina & - & 0.1 & - & - & - & 2.4 & 2.6 & $1 \%$ \\
\hline Cuba & - & - & - & - & - & 5.4 & 5.4 & $2 \%$ \\
\hline Total & 21 & 178 & 4 & 0 & 35 & 104 & 341.3 & $100 \%$ \\
\hline Sahre & $6 \%$ & $52 \%$ & $1 \%$ & $0 \%$ & $10 \%$ & $31 \%$ & $100 \%$ & \\
\hline
\end{tabular}

Dividing the total water consumption by the total biofuel consumption, an average water consumption of $1.9 \mathrm{~m}^{3} / \mathrm{GJ}$ for biodiesel and $3.3 \mathrm{~m}^{3} / \mathrm{GJ}$ for bioethanol has been determined. It should be noted that in both cases, the specific water consumption can be very diverse depending on the underlying crop and country. While no irrigation is needed to cultivate crops for biodiesel in the UK, Poland, and Germany, on average $90 \mathrm{~m}^{3}$ of irrigation water are consumed to produce 1 GJ of biodiesel in Spain or from Spanish crops. Bioethanol or underlying crops can be produced without irrigation in Czech Republic and Switzerland. In contrast, the production of bioethanol or underlying crops in Portugal consumes $86 \mathrm{~m}^{3} / \mathrm{GJ}$. 
The analysis of water consumption for fossil fuels resulted in water consumption figures of $0.032 \mathrm{~m}^{3} / \mathrm{GJ}$ for diesel and $0.081 \mathrm{~m}^{3} / \mathrm{GJ}$ for gasoline. Hence, biodiesel causes about 70 times and bioethanol 44 times the water consumption compared to their fossil alternatives (Figure 2). Taking into account these significant differences, it is assumed that data availability related differences in the reference years (origin of feedstock 2010, water consumption of biofuels 1996-2005, and fossil fuels 2013) do not change the general finding from this study.

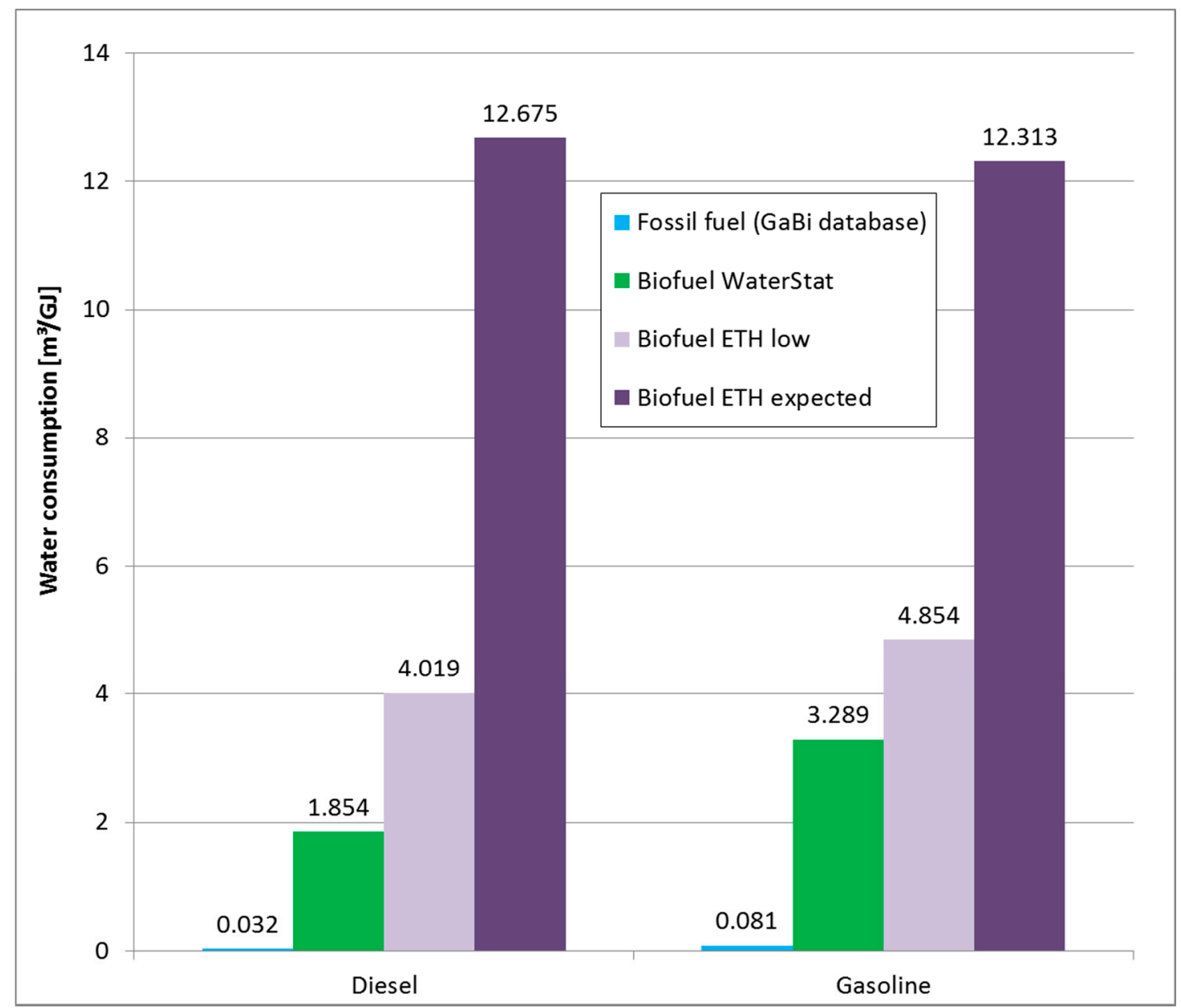

Figure 2. Water consumption per unit of energy derived from average fossil diesel, biodiesel, fossil gasoline, and bioethanol consumed in Europe. The figure includes the estimate form the WaterStat database [11], and the ETH database low [25] and normal estimate [26] included as a sensitivity check.

\subsection{Uncertainties in Volumetric Results}

Since irrigation water consumption data is based on global models, uncertainties in the estimates should be analyzed. Therefore, additional irrigation water consumption data from the ETH databases $[25,26]$ has been applied which provides an expected and a low estimate for the blue water footprint of biofuels. As shown in Tables S1-S4 in the supporting information, the water consumption estimates per biofuels or specific origin can vary considerably, depending on the model used: Spain is getting a lower share in the blue water footprint of EU's biofuel consumption, while France, Romania and Argentina get a higher percentage. This is based on differences in the underlying ETH model 
which shows relatively high differences in water consumption for some regions compared to WaterStat. While the ETH data is based on spatially explicitly modeled yields, WaterStat calculates the yields as a function of water availability (and therefore a function of modeled irrigation). ETH data corrects calculated theoretical irrigation water demand based on a spatially explicit irrigation dataset, while WaterStat calculates water availability of precipitation and irrigation in soil moisture as a function of a different irrigation model. Since both approaches have advantages and disadvantages and cannot reflect the real water consumption, the observed difference can be expected, since all the input data required for the models are uncertain, especially since they are available on high spatial resolution $(\sim 10 \mathrm{~km})$ on global coverage.

However, total global agricultural water consumption of the WaterStat database is between the ETH expected and low estimates, so there is no general trend between the two databases - which appears to be the case according to the results shown in this paper. Based on the analysis in this paper, the average water consumption for EU results to $4.0-12.7 \mathrm{~m}^{3} / \mathrm{GJ}$ for biodiesel and $4.9-12.3 \mathrm{~m}^{3} / \mathrm{GJ}$ for bioethanol, which is considerably higher than the numbers based on WaterStat (Figure 2). This variability among different data also indicates that the difference of EU bioethanol and biodiesel consumption is not significant and more detailed assessment of specific origins is needed to compare two specific options. Uncertainty is even more relevant since the variability of blue water consumption for a crop within one country can be very high as reported for the ETH model [21]: for soybean production, the coefficient of variation (CV) is 2.9 for Argentina and 2.7 for the US, while for Spain, the $\mathrm{CV}$ of sunflower and maize production is 0.9 .

However, the results based on the two databases agree that the blue water footprint of biofuels is $\sim 2$ orders of magnitude higher compared to their fossil alternatives.

The average water consumption caused by European biofuel consumption is significantly lower than the world average water consumption of biofuels. Based on ETH data, the global average biofuel production has roughly 2-2.5 times the water consumption of EU consumption (Table S5). Based on WaterStat data, the global average is around two orders of magnitude higher for biodiesel $\left(217 \mathrm{~m}^{3} / \mathrm{GJ}\right.$ for soybean to $335 \mathrm{~m}^{3} / \mathrm{GJ}$ for jatropha) and one order of magnitude for bioethanol $\left(18 \mathrm{~m}^{3} / \mathrm{GJ}\right.$ for cassava to $182 \mathrm{~m}^{3} / \mathrm{GJ}$ for sorghum) [8]. This can be explained by the fact that $60 \%$ and $79 \%$ of the crops underlying European biodiesel and bioethanol consumption are grown within the European Union where, except for Southern European countries, irrigation demand is relatively low. Moreover, as it can be seen in Tables 3 and 4, also the imported crops are derived from countries with mainly low irrigation needs, such as Soybean from Argentina or sugar cane from Brazil. However, the enormous difference between European and global average water consumption might also be a result of the high model uncertainty as discussed above.

Since absolute volumes do not allow for an assessment of local impacts, a regionalized water inventory has been established for both fossil and biofuels according to the methodology described in the previous chapter. The following maps show the relative local shares of water consumed in the production of average biodiesel and fossil diesel (Figure 3a) and bioethanol and fossil gasoline (Figure 3b). Taking into account the relative presentation, the maps allow for a comparison of local water consumption per individual fuel only. Hence, the bars of different fuels cannot be compared to each other since they are based on different absolute water consumption figures per GJ of fuel. 


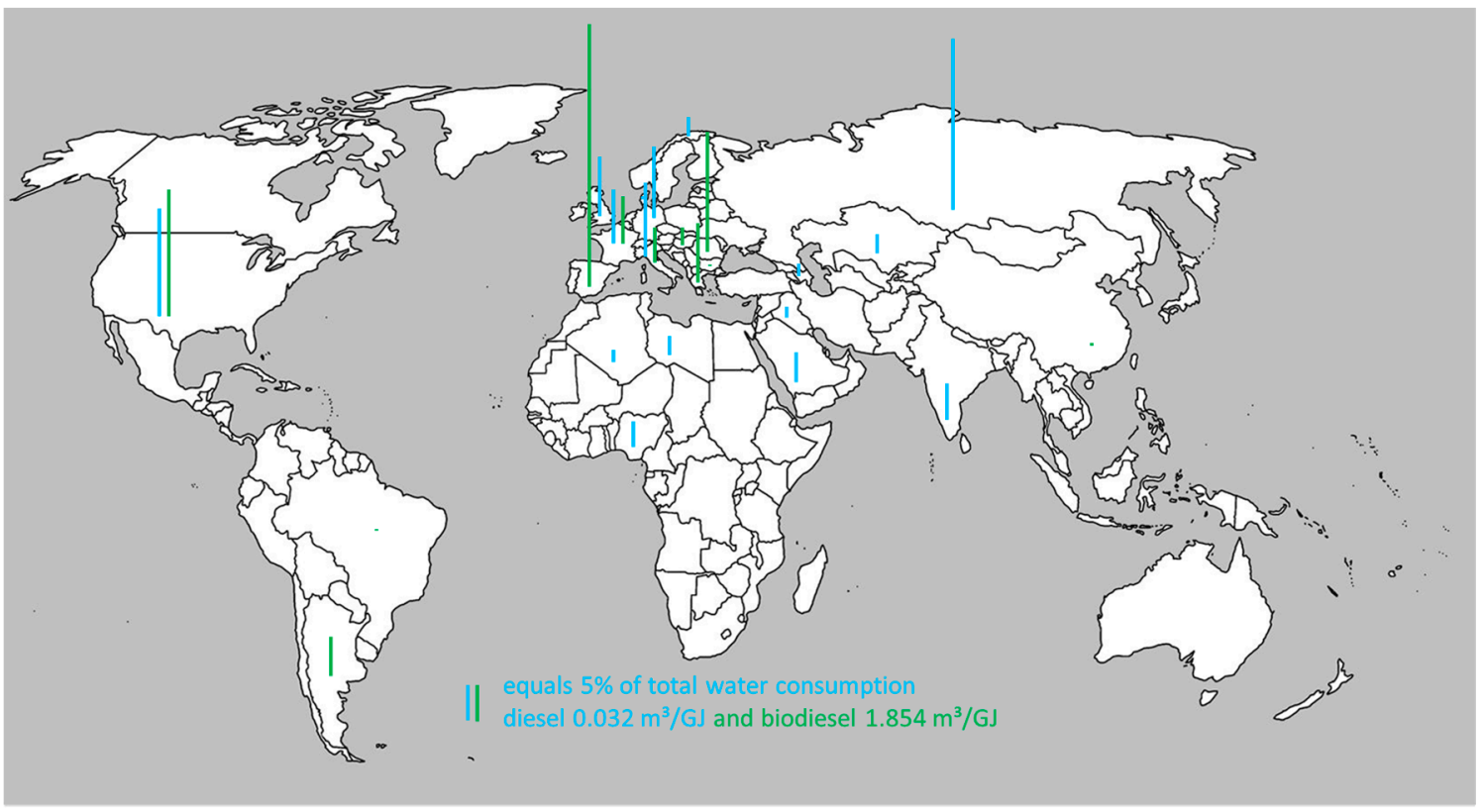

(a)

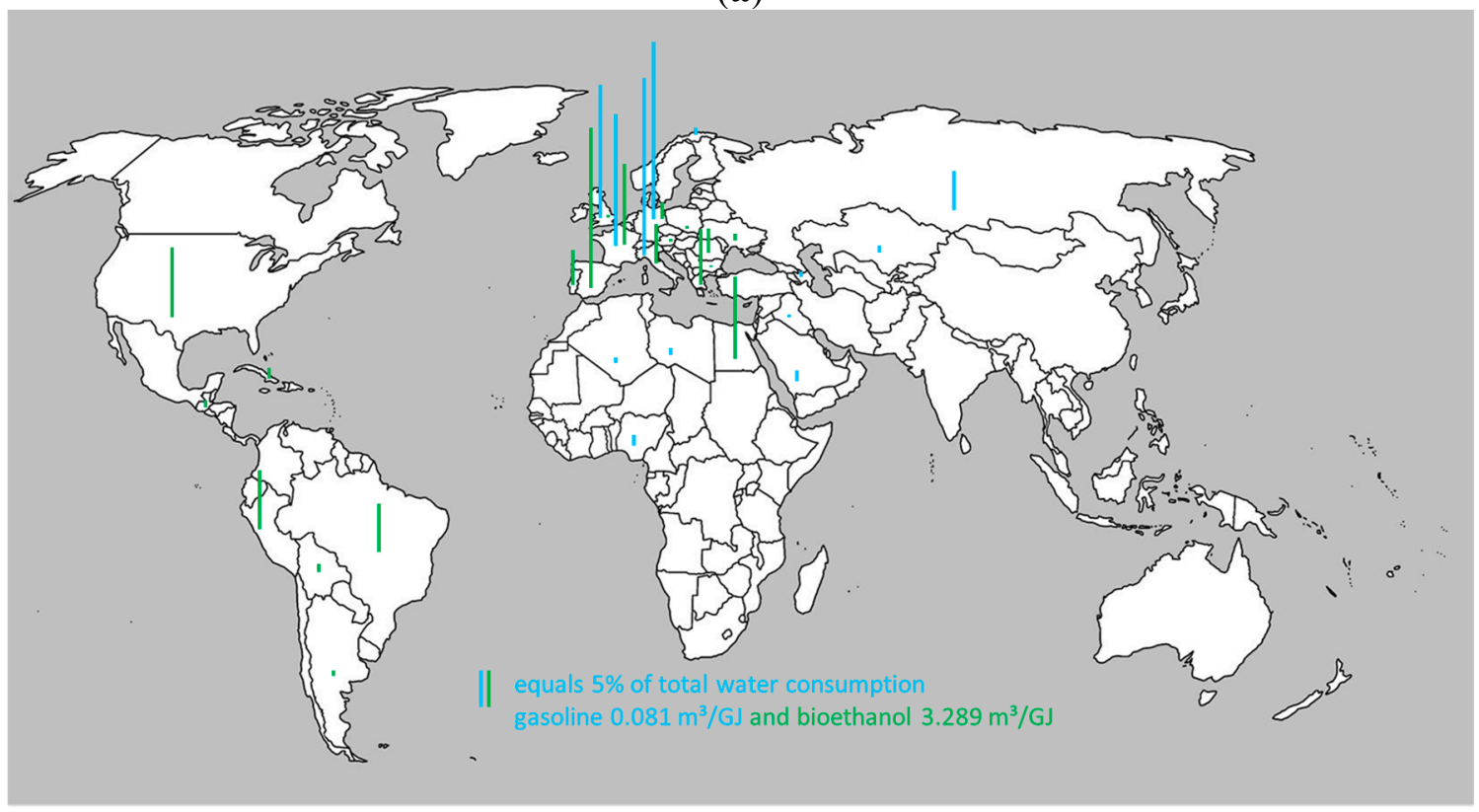

(b)

Figure 3. Relative local water consumption occurring in the production of (a) fossil diesel (blue bars) and biodiesel (green bars) and (b) gasoline (blue bars) and bioethanol (green bars) consumed in the European Union.

As it can be seen from the maps, water consumption in biodiesel and diesel production takes place in 12 and 16 countries, respectively. The production of bioethanol and gasoline consumes water in 23 and 14 countries. For biodiesel, 72\% of the water consumption occurs in Spain (sunflower seed), the US (soybean), and Romania (sunflower seed and soybean). For bioethanol, water consumption is distributed more homogeneously. Nevertheless, Spain (22\%, mainly maize and sugar beet), Egypt (11\%, sugar cane), France (11\%, mainly maize), and the US (10\%, mainly maize) can be regarded as the main contributors. The relative spatial distribution for biofuel based on the alternative database is shown per country in the supporting information (Figure S1) indicating differences in relative importance. 


\subsection{Impact Assessment}

By multiplying the spatially explicit water inventories shown in Figure 3 with the corresponding regional characterization factors provided by the WAVE model [19] and the model of Pfister and colleagues [20], impacts from water consumption in these countries have been assessed (Figure 3). It should be noted that for biofuels only the consumption figures determined based on WaterStat are considered in this impact assessment. Since only water consumption but no water pollution is considered in this work, this study represents a water availability footprint according to ISO 14046 [9].

Comparing biodiesel and fossil diesel, it has been shown that the differences on the inventory level (varying by a factor of 60) are in a similar range on the impact assessment level (factor 55-74). The only exception from this trend is the impact category damage to human health. Here, biodiesel causes similar impacts as fossil diesel despite the significantly higher water consumption. This can be explained by the locations of water consumption in biodiesel production. As shown in Figure $3 \mathrm{a}$, water consumption occurs mainly in Europe and in the US. Even though physical water scarcity is relevant in many of those countries, their high degree of development avoids health damages resulting from water stress.

Concerning bioethanol, Figure 4 shows that differences on the impact assessment level are significantly higher (factor 64-246) than on the inventory level (factor 40). The reason for this can be found in the origin of the feedstock (Figure 3b) and the local water scarcity which leads to higher differences on the impact than on the volumetric level compared to gasoline. For instance, crops grown for European bioethanol consumption cause irrigation water consumption in water stressed countries like Egypt or Spain, while gasoline production has main water consumption in North-Western Europe (Figure $3 b$ ) with low water scarcity and no human health impacts.

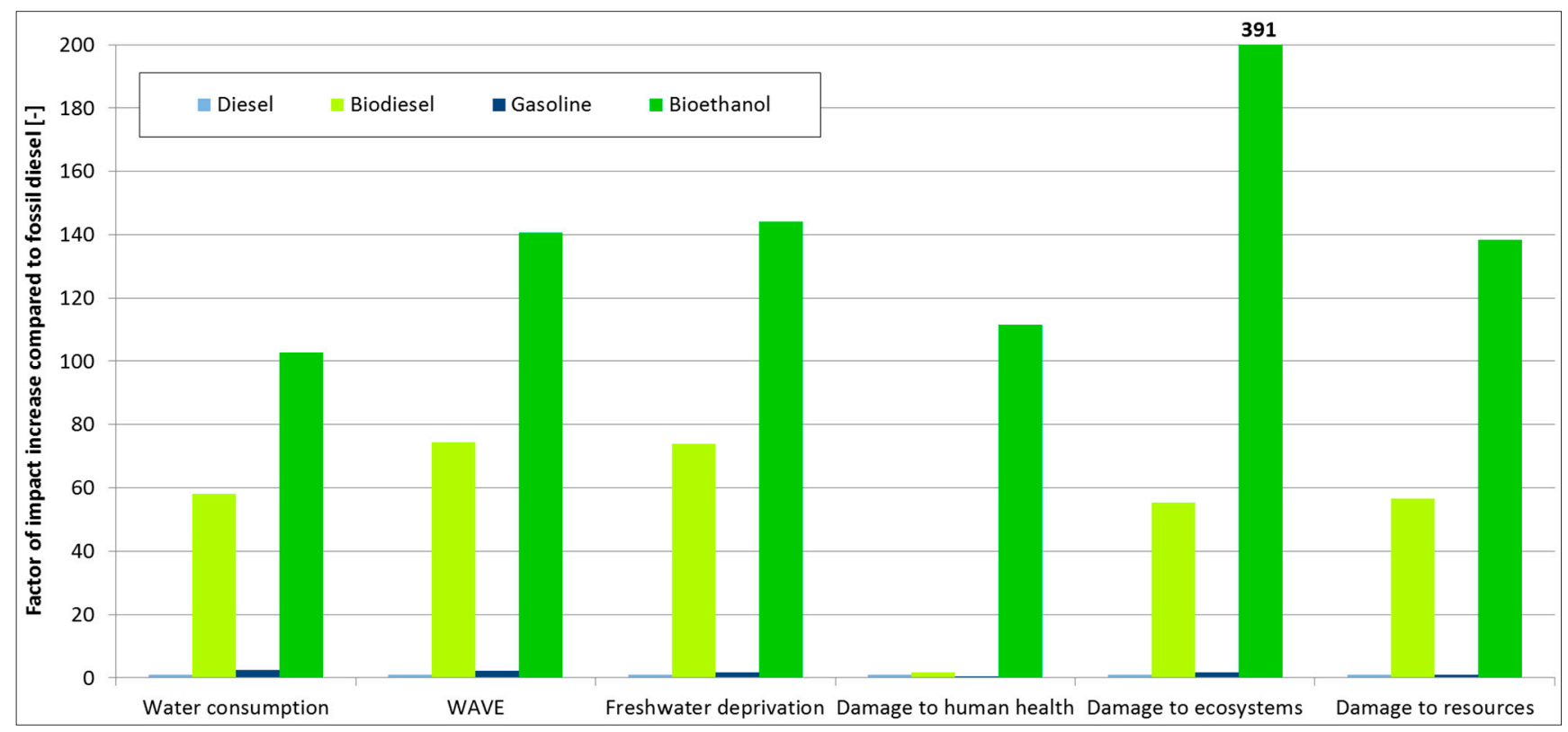

Figure 4. Water consumption and resulting local impacts presented in relation to fossil diesel, i.e., factor of increase compared to fossil diesel in each category. 
In order to identify the most relevant crops and countries, the origin of the impacts resulting from water consumption have been analyzed in more detail by means of the impact category freshwater depletion from the WAVE model [19]. As it can be seen from Figure 5a, the irrigation of mainly sunflower seed in Spain causes $50 \%$ of the impacts, even though it constitutes less than $0.9 \%$ of the feedstock in European biodiesel production. In case of bioethanol production, the irrigation of sugar cane in Egypt, which constitutes only $0.7 \%$ of European bioethanol production, causes $20 \%$ of the impacts. For agricultural products, where blue water consumption is largely depending on climate this effect is generally observed: places with high irrigation typically show higher water scarcity. However, it should be noted that average country factors have been used for both water consumption figures and characterization factors. Especially in large countries like the US or China, an evaluation on the level of river basins is more adequate. Moreover, considering the uncertainty of blue water estimates discussed above, the distribution of impacts should be considered as indicative rather than absolute shares.

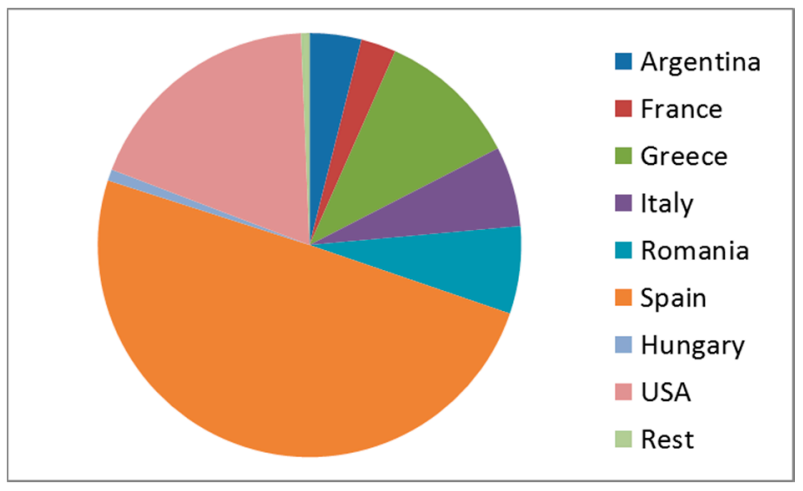

(a)

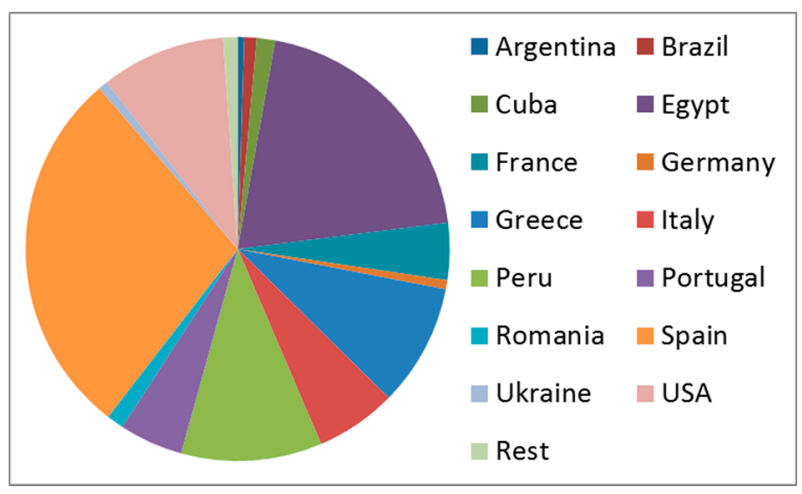

(b)

Figure 5. Relative contribution of countries to the results of the impact category freshwater depletion from the WAVE model [19] for (a) biodiesel and (b) bioethanol.

\subsection{Influence of Biofuels on Carbon and Water Footprint of Cars along the Life Cycle}

So far, water consumption and related impacts have been analyzed for fossil fuels and biofuels solely. Yet, taking a holistic perspective, the influence of biofuels on the water footprint of a car along its entire lifecycle is more relevant. In order to address this aspect and to compare a car's carbon and water footprint, the global warming potential (Figure 6a), the volumetric water consumption (Figure 6b) and the resulting impacts (Figure 6c) of a car run by gasoline and bioethanol has been determined throughout the life cycle as described in Section 2.2. It should be noted that fuel production is assigned to the use phase of a car.

As it can be seen in Figure 5a, bioethanol can reduce the carbon footprint of a car by about $50 \%$ compared to a car run by fossil gasoline. However, taking into account the 40 times higher water consumption of bioethanol compared to fossil gasoline, the life cycle based water consumption increases from about 105 to $1979 \mathrm{~m}^{3}$ (Figure 6b). On the impact assessment level (Figure 6c), the increase in freshwater depletion is even more significant which can be explained by the local water scarcity in the countries providing the underlying crops. 


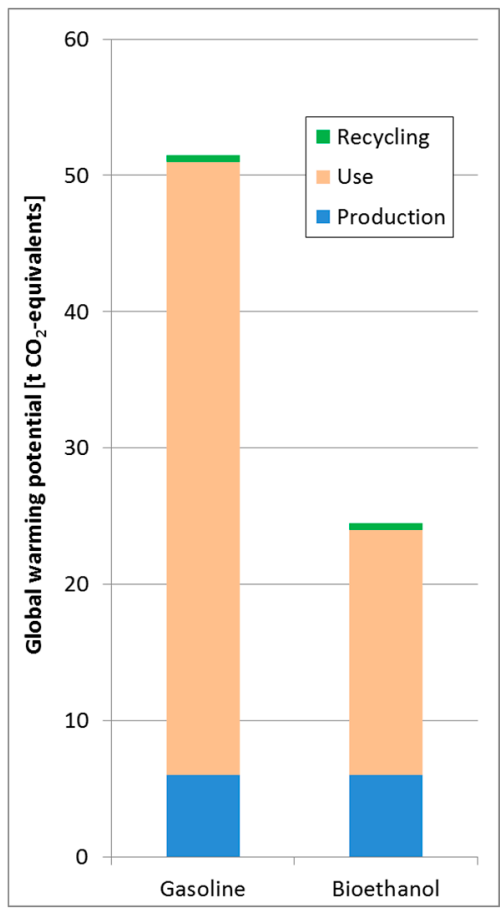

(a)

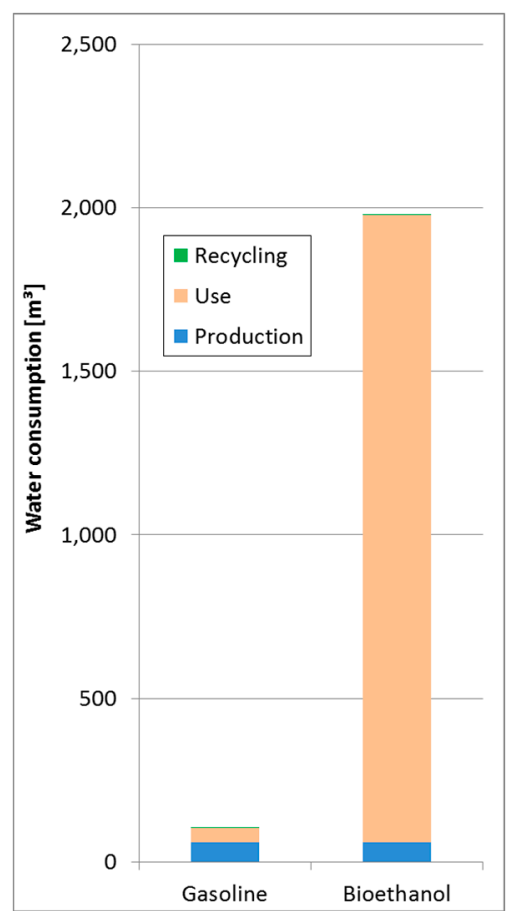

(b)

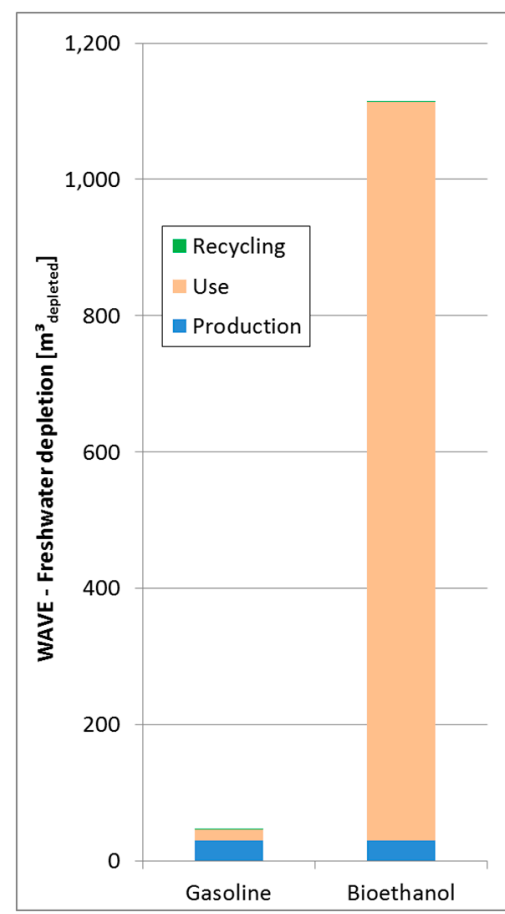

(c)

Figure 6. (a) Global warming potential (b) Volumetric water consumption (c) Impacts of water consumption (WAVE-freshwater depletion) along the life cycle of an average passenger car run by gasoline and bioethanol.

Even potential uncertainties in the water consumption figures of the car's production, fuel production, and recycling phase are not expected to affect the main finding of this work: European biofuels cause significantly higher water consumption in car transportation than their fossil alternatives. Thus, a reduction in a car's carbon footprint achieved by the use of biofuels is accompanied by a significant increase in its water footprint.

\section{Conclusions}

While biofuels are promoted to decrease the carbon footprint of car transportation, little information regarding the global water footprint of biofuels consumed in Europe is available. This study compares the water consumption and associated impacts resulting from the production of $1 \mathrm{GJ}$ fuel of average European biodiesel, diesel, bioethanol, and gasoline.

The ultimate origin of feedstock underlying European biodiesel and bioethanol consumption has been combined with the irrigation requirements of different crops in different countries. As a result, a (blue) water consumption of $1.9 \mathrm{~m}^{3}$ per GJ of European biodiesel and $3.3 \mathrm{~m}^{3}$ per GJ of bioethanol has been determined. Even though this represents an increase by a factor of 60 and 40 compared to fossil diesel and gasoline, these figures are low compared to global average water consumption data for biofuels. However, the estimates are quite uncertain as a comparison with an alternative database resulted in higher water consumption (by a factor 1.5 to 6.8 ).

In order to assess potential local impacts resulting from this water consumption regional information on where the water consumption occurs is required. This analysis revealed that average European biodiesel causes water consumption in 12 countries and bioethanol is responsible for water 
consumption in 23 countries. In contrast, fossil diesel and gasoline are responsible for water consumption in 16 and 14 countries, respectively.

These regional water consumption figures have been multiplied by local characterization factors derived from the WAVE model [19] and the impact assessment method developed by Pfister and colleagues [20]. While the difference between biodiesel and fossil diesel is similar on the inventory and the impact assessment levels (factor 55-74, except human health impacts), bioethanol shows larger differences compared to gasoline on the impact level (factor 64-246) than on the volumetric level (factor 40). The reason for the significantly higher impacts of biofuels compared to fossil fuels can be found in the fact that relatively large shares of water consumption in the production of biofuels are caused in relatively dry countries. For instance, the irrigation of mainly sunflower seed in Spain causes $52 \%$ of the impacts, even though it constitutes only $0.5 \%$ of the feedstock in European biodiesel production. In case of bioethanol production, the irrigation of sugar cane in Egypt, which constitutes only $0.4 \%$ of European bioethanol production, causes $20 \%$ of the impacts. Yet, it should be noted that these conclusions are attenuated when considering the ETH databases.

By means of a case study on passenger cars, the trade-off between water and carbon footprints has been illustrated. While biofuels generally cause less greenhouse gas emissions than fossil fuels (factor $\sim 0.5$ ), the water consumption (factor $\sim 19$ ) and especially the resulting local impacts (factor $\sim 24$ ) are more severe.

\section{Acknowledgments}

The authors wish to express sincere thanks to Ivetta Gerasimchuk (Chatham House) who provided insight into the data used to determine the origin of feedstock used for biofuel production. Moreover, the valuable feedback of Gerhard Brankatschk (OVID) concerning crop cultivation and biofuel production is highly appreciated.

\section{Author Contributions}

Markus Berger accomplished the survey and wrote a draft of the manuscript. Stephan Pfister added an analysis and discussion by using alternative ETH databases for the irrigation water consumption needed to produce the crops used for biodiesel and bioethanol production. Vanessa Bach developed the software tool which creates the spatially explicit water inventories used as a base for the impact assessment of this work. Matthias Finkbeiner reviewed the manuscript and provided valuable comments to deepen the discussion and conclusion.

\section{Conflicts of Interest}

The authors declare no conflict of interest. 


\section{References}

1. Directive 2009/28/EC. Directive 2009/28/ec of the european parliament and of the council of 23 april 2009 on the promotion of the use of energy from renewable sources. Available online: http://eur-lex.europa.eu/legal-content/en/TXT/?uri=CELEX:32009L0028 (accessed on 6 February 2015).

2. Gerasimchuk, I. Energy, Environment and Resources eer pp 2012/04: Biofuel Policies and Feedstock in the EU; Chatham House: London, UK, 2013.

3. ISO. Environmental Management-Life Cycle Assessment-Requirements and Guidelines (ISO 14044:2006); International Organisation for Standardisation, Ed.; ISO: Geneva, Switzerland, 2006.

4. ISO. ISO 14064-1 Greenhouse Gases-Part 1-Specification for the Quantification, Monitoring and Reporting of entity Emissions and Removals; ISO 14064-2 Greenhouse Gases-Part 2-Specification for the Quantification, Monitoring and Reporting of Project Emissions and Removals; ISO 14064-3 Greenhouse Gases-Part 3-Specification and Guidance for Validation, Verification and Certification; International Organization for Standardization, Ed.; ISO: Geneva, Switzerland, 2006.

5. Zah, R.; Böni, H.; Gauch, M.; Hischier, R.; Lehmann, M.; Wäger, P. Ökobilanz von Energieprodukten: Ökologische Bewertung von Biotreibstoffen; Empa, Technology and Society Lab: St. Gallen, Switzerland, 2007.

6. Sanchez, S.T.; Woods, J.; Akhurst, M.; Brander, M.; O’Hare, M.; Dawson, T.P.; Edwards, R.; Liska, A.J.; Malpas, R. Accounting for indirect land-use change in the life cycle assessment of biofuel supply chains. J. R. Soc. Interface 2012, 9, 1105-1119.

7. Finkbeiner, M. Indirect land use change-help beyond the hype? Biomass Bioenergy 2014, 62, $218-221$.

8. Gerbens-Leenes, W.; Hoekstra, A.Y.; van der Meer, T.H. The water footprint of bioenergy. Proc. Natl. Acad. Sci. USA 2009, 106, 10219-10223.

9. ISO. Water Footprint-Principles, Requirements and Guidance; International Organization for Standardization, Ed.; ISO: Geneva, Switzerland, 2014.

10. Gerbens-Leenes, W.; Hoekstra, A.Y. The water footprint of biofuel-based transport. Energy Environ. Sci. 2011, 4, 2658-2668.

11. Mekonnen, M.M.; Hoekstra, A.Y. The green, blue and grey water footprint of crops and derived crop products. Hydrol. Earth Syst. Sci. 2011, 15, 1577-1600.

12. Bayart, J.B.; Bulle, C.; Koehler, A.; Margni, M.; Pfister, S.; Vince, F.; Deschenes, L. A framework for assessing off-stream freshwater use in 1ca. Int. J. Life Cycle Assess. 2010, 15, 439-453.

13. Ecofys. Renewable energy progress and biofuels sustainability. Available online: http://www.ecofys.com/en/publication/progress-in-renewable-energy-and-biofuels-sustainability/ (accessed on 7 May 2015).

14. FAOSTAT. Food and aggriculture organization of the united nations statistical devision. Available online: http://faostat3.Fao.Org/home/e (accessed on 15 January 2015).

15. PE International. Gabi LCI database. Available online: http://www.gabi-software.com (accessed on 27 March 2015). 
16. Berger, M.; Finkbeiner, M. Methodological challenges in volumetric and impact oriented water footprints. J. Ind. Ecol. 2013, 17, 79-89.

17. Berger, M.; Warsen, J.; Krinke, S.; Bach, V.; Finkbeiner, M. Water footprint of european cars: Potential impacts of water consumption along automobile life cycles. Environ. Sci. Technol. 2012, 46, 4091-4099.

18. Martinez-Blanco, J.; Berger, M.; Bach, V.; Finkbeiner, M. Promoting the application of water footprints: A tool for the regionalization of generic water inventories. In Proceedings of the Life Cycle Assessment XIII, Orlando, FL, USA, 1-3 October 2013.

19. Berger, M.; van der Ent, R.; Eisner, S.; Bach, V.; Finkbeiner, M. Water accounting and vulnerability evaluation (wave) - Considering atmospheric evaporation recycling and the risk of freshwater depletion in water footprinting. Environ. Sci. Technol. 2014, 48, 4521-4528.

20. Pfister, S.; Koehler, A.; Hellweg, S. Assessing the environmental impacts of freshwater consumption in lca. Environ. Sci. Technol. 2009, 43, 4098-4104.

21. Flörke, M.; Kynast, E.; Bärlund, I.; Eisner, S.; Wimmer, F.; Alcamo, J. Domestic and industrial water uses of the past 60 years as a mirror of socio-economic development: A global simulation study. Glob. Environ. Change 2013, 23, 144-156.

22. Kim, H.C.; Wallington, T.J.; Mueller, S.A.; Berdish, D.; Bras, B.; Tejada, F.; Guldberg, T. Water use in the life cycle of light-duty vehicles. In Proceedings of the 10th International Conference on EcoBalance, Tokyo, Japan, 21-23 November 2012.

23. Daimler. Mercedes-benz models with environmental certificates. Available online: http://www.Daimler.Com/sustainability/product-responsibility (accessed on 18 April 2015).

24. Van den Bos, A.; Hamelinck, C. Greenhouse Gas Impact of Marginal Fossil Fuel Use; Ecofys: Utrecht, The Netherlands, 2014.

25. Pfister, S.; Bayer, P.; Koehler, A.; Hellweg, S. Environmental impacts of water use in global crop production: Hotspots and trade-offs with land use. Environ. Sci. Technol. 2011, 45, 5761-5768.

26. Pfister, S.; Bayer, P. Monthly water stress: Spatially and temporally explicit consumptive water footprint of global crop production. J. Clean. Prod. 2014, 73, 52-62.

(C) 2015 by the authors; licensee MDPI, Basel, Switzerland. This article is an open access article distributed under the terms and conditions of the Creative Commons Attribution license (http://creativecommons.org/licenses/by/4.0/). 